\title{
Rapid Growth of
}

Dermatofibrosarcoma

\section{Protuberans Associated with} Bilateral Adrenalectomy for Cushing's Syndrome

\author{
Sadanori Furudate Taku Fujimura Akira Hashimoto \\ Setsuya Aiba
}

Department of Dermatology, Tohoku University Graduate School of Medicine, Sendai, Japan

\section{Key Words}

Bilateral adrenalectomy - COL1A1/PDGFB fusion gene - Cushing's syndrome ·

Dermatofibrosarcoma protuberans

\begin{abstract}
We describe a 50-year-old Japanese patient with dermatofibrosarcoma protuberans (DFSP) rapidly growing after bilateral adrenalectomy for Cushing's syndrome that reduced the serum level of cortisol from 17.1 to $0.8 \mathrm{mg} / \mathrm{dl}$. It is known that glucocorticoids decrease the transcriptions of the COL1A1 gene and the PDGFB gene, which is under the direct control of the COL1A1 gene in most DFSP. Therefore, the hypersecretion of glucocorticoids in Cushing's syndrome might suppress the development of DFSP. To the best of our knowledge, this is the first case of rapid growth of DFSP that may be associated with bilateral adrenalectomy for Cushing's syndrome.
\end{abstract}

\section{Introduction}

Dermatofibrosarcoma protuberans (DFSP) is a rare skin sarcoma known for its indolent and low metastatic potential. Recently, DFSP has been shown to be characterized by a reciprocal translocation, $\mathrm{t}(17 ; 22)(\mathrm{q} 22 ; \mathrm{q} 13)$, and a supernumerary ring chromosome derived from the translocation $\mathrm{r}(17 ; 22)$ [1]. The translocation results in a fusion of two genes, COL1A1 and PDGFB [2]. The COL1A1 gene is located at 17q21-22 and encodes the a1 (1) chain of type I collagen. The PDGFB gene is located at $22 \mathrm{q} 13$ and encodes the $\mathrm{B}$ chain of the platelet-derived growth factor (PDGF) ligand. The fusion causes a 
deregulation of the $P D G F B$ gene by deleting its exon 1 and placing it under the direct control of the COL1A1 gene. This rearrangement leads to an unregulated production of the growth factor, which seems to play an important role in the development of DFSP [3]. Epidemiological studies revealed that more than $95 \%$ of DFSP present anomalies on the $17 \mathrm{q} 22$ and $22 \mathrm{q} 13$ chromosomal regions, leading to the fusion of the COL1A1 and PDGFB genes $[4,5]$. In approximately $5 \%$ of cases, no COL1A1-PDGFB fusion was found, suggesting that other genes might be involved in the DFSP pathogenesis [6].

Cushing's syndrome is characterized by a chronic and excessive exposure to endogenous glucocorticoids (GCs). Chronic GC excess has detrimental effects on the skin, leading to atrophy and impaired wound healing [7]. Several in vitro studies have shown that GCs induce alterations in extracellular matrix homeostasis, such as collagen synthesis and the expression of matrix metalloproteinases, leading to a reduction in the collagen mass [8-10]. In other words, increased doses of GCs induce a catabolic phenotype in skin fibroblasts in vivo and in vitro.

In this paper, we describe a patient with a rapid onset of DFSP associated with bilateral adrenalectomy for Cushing's syndrome. To our knowledge, there is no English report of DFSP associated with bilateral adrenalectomy for Cushing's syndrome.

\section{Case Report}

A 50-year-old Japanese woman visited our outpatient clinic with a 20-year history of an asymptomatic, about $3 \mathrm{~mm}$ in diameter, subcutaneous nodule on her breast. One year before, this nodule rapidly enlarged after she underwent bilateral adrenalectomy for Cushing's syndrome. On her initial visit, physical examination revealed a brown-colored, elastic hard, well-demarcated nodule on the left side of her breast (fig. 1). The tumor mass was $20 \times 18 \mathrm{~mm}$ in size. An excisional biopsy showed densely packed, monomorphic, plump, spindle cells arranged in a storiform pattern in the central area of the tumor nodule and spindle cells infiltrating into the subcutis of the peripheral lesion (fig. 2a, b). The tumor cells were positive for CD34 and negative for factor XIIIa (fig. 2c, d), SMA, and S100 (data not shown). Based on the above-mentioned findings, we diagnosed this patient as having DFSP. Interestingly, the serum levels of cortisol before and after bilateral adrenalectomy were 17.1 and 0.8 $\mathrm{mg} / \mathrm{dl}$, respectively. We excised the tumor with a $3-\mathrm{cm}$ surgical margin of mammary gland tissue. A half year after surgical treatment, there was no evidence of local tumor recurrence.

\section{Discussion}

This case is unique in suggesting an association between DFSP and Cushing's syndrome, and, to the best of our knowledge, this is the first case report of DFSP coexisting with Cushing's syndrome.

GCs bind to receptors in the cytoplasm to form complexes that translocate into the nucleus to regulate downstream targets by binding to glucocorticoid response elements. Previously, Mahonen et al. [11] reported that dexamethasone treatment decreased the transcription of the COL1A1 gene. Schoepe et al. [12] reported that, in a skin model, the inhibition of COL1A1 mRNA expression correlated with the dose and type of GCs (e.g. hydrocortisone, prednicarbate, mometasone-17-furoate, and clobetasol-17-propionate). Thus, the increase of cortisol in Cushing's syndrome may suppress the transcription of the COL1A1/PDGFB fusion gene in DFSP. In our case, the tumor mass dramatically 
enlarged 1 month after bilateral adrenalectomy for Cushing's syndrome, which was coincident with the sudden reduction of serum cortisol (from 17.1 to $0.8 \mathrm{mg} / \mathrm{dl}$ ).

Supportive therapy for DFSP is still limited. Kerob et al. [5] assessed the treatment of 25 cases of nonresectable DFSP patients with imatinib mesylate. In their report, although imatinib mesylate targets PDGF- $\beta$ and can be effective for DFSP, a clinical response was achieved in only $36 \%$ of cases. The authors concluded that other reagents to treat nonresectable DFSP are necessary [5]. Our present report sheds light on the suppressive effect of GCs on the development of DFSP, which could lead to therapeutic use of GCs, although in vitro studies regarding the effect of GCs on the growth of cultured DFSP are a prerequisite.

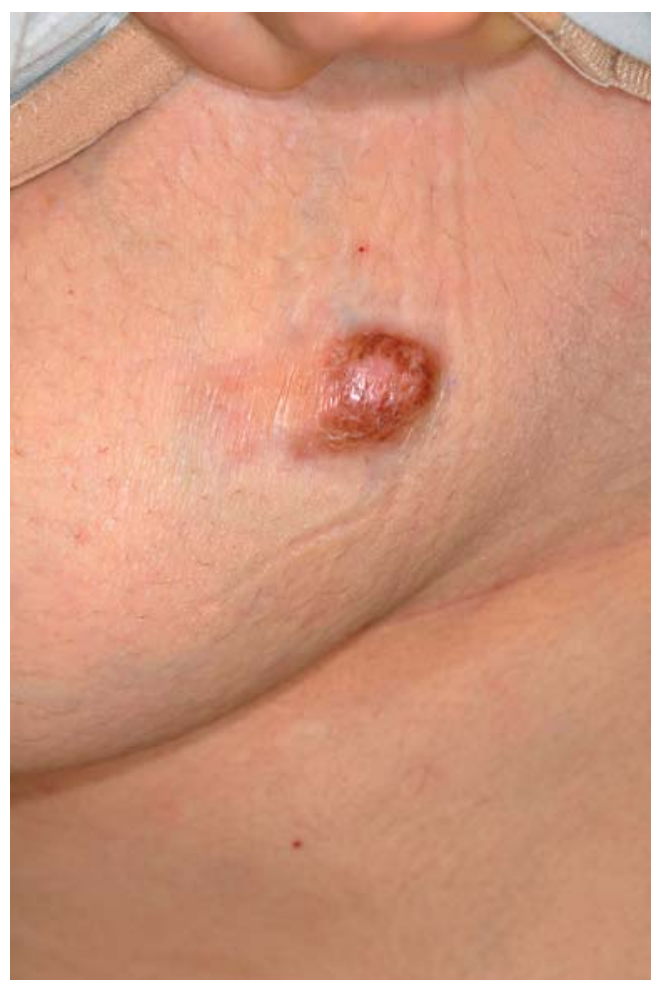

Fig. 1. Brown-colored, elastic hard, well-demarcated nodule on the left side of the breast. The tumor mass was $35 \times 50 \mathrm{~mm}$ in size. 


\begin{tabular}{r|l|l|l}
$\begin{array}{c}\text { Case Reports in } \\
\text { Dermatology }\end{array}$ & $\begin{array}{l}\text { Case Rep Dermatol 2011;3:113-117 } \\
\text { DOI: } 10.1159 / 000329000\end{array}$ & $\begin{array}{l}\text { Published online: } \\
\text { May 20, 2011 }\end{array}$ & $\begin{array}{l}\text { I 2011 S. Karger AG, Basel } \\
\text { ISSN 1662-6567 } \\
\text { www.karger.com/cde }\end{array}$ \\
\hline
\end{tabular}
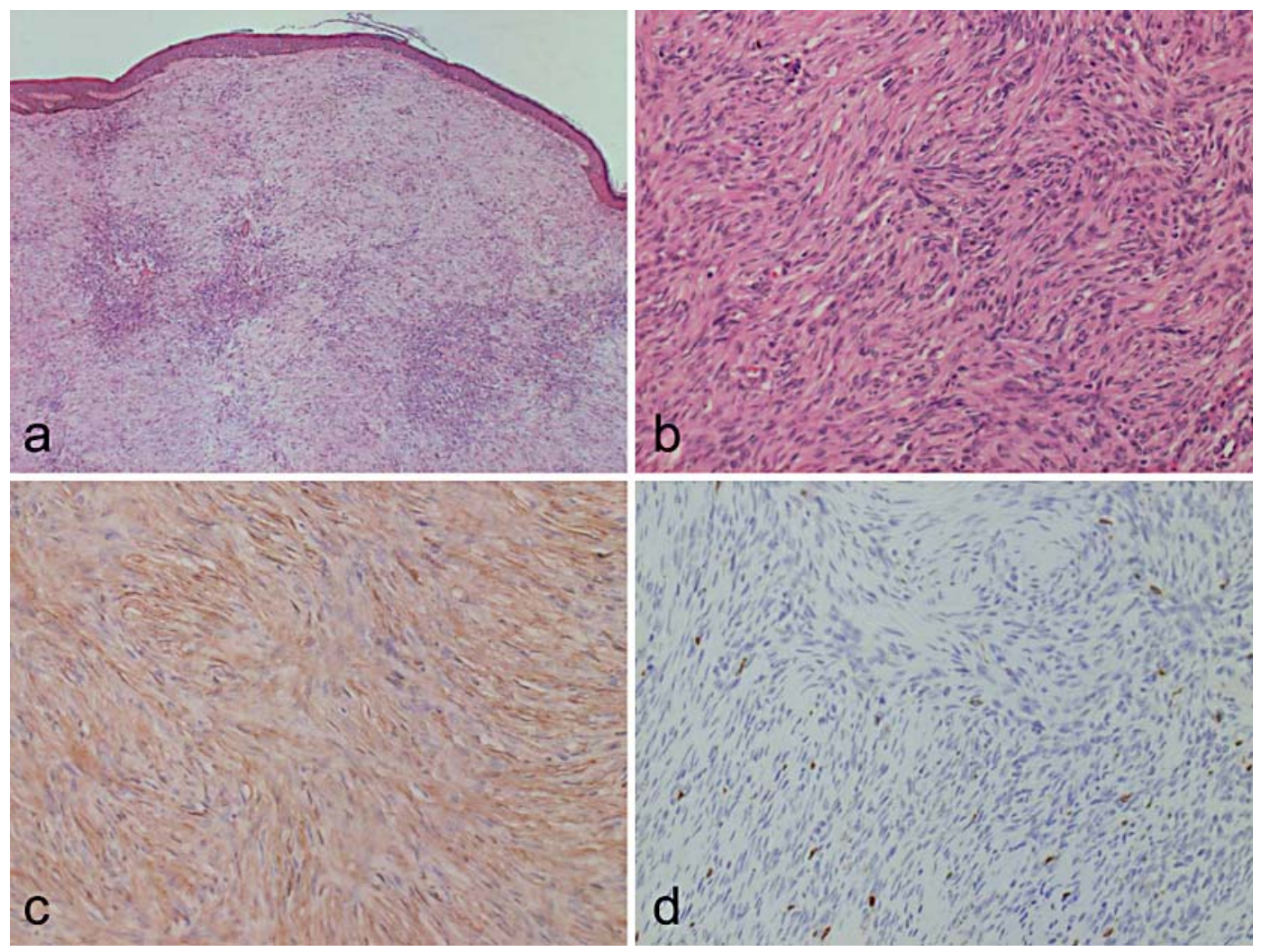

Fig. 2. Densely packed, monomorphic, plump, spindle cells arranged in a storiform pattern in the central area of the tumor nodule, and, in the peripheral lesion, spindle cells diffusely infiltrating around the tumor (a, b). Immunohistochemical staining for CD34 (c) and Factor XIIIa (d). a Original magnification $\times 100$; $\mathbf{b}-\mathbf{d}$ original magnification $\times 400$.

\section{References}

$\checkmark 1$ Pedeutour F, Simon MP, Minoletti F, Barcelo G, Terrier-Lacombe MJ, Combemale P, Sozzi G, Ayraud N, Turc-Carel C: Translocation, $\mathrm{t}(17 ; 22)(\mathrm{q} 22 ; \mathrm{q} 13)$ in dermatofibrosarcoma protuberans: a new tumor-associated chromosome rearrangement. Cytogenet Cell Genet 1996;72:171-174.

-2 Simon MP, Pedeutour F, Sirvent N, Grosgeorge J, Minoletti F, Coindre JM, Terrier-Lacombe MJ, Mandahl N, Craver RD Blin N, Sozzi G, Turc-Carel C, O’Brien KP, Kedra D, Fransson I, Guilbaud C, Dumanski JP: Deregulation of the platelet-derived growth factor B-chain gene via fusion with collagen gene COL1A1 in dermatofibrosarcoma protuberans and giant-cell fibroblastoma. Nat Genet 1997;15:95-98.

- 3 Wang J, Morimitsu Y, Okamoto S, Hisaoka M, Ishida T, Sheng W, Hashimoto H: COL1 A1-PDGFB fusion transcripts in fibrosarcomatous areas of six dermatofibrosarcomas protuberans. J Mol Diagn 2000;2:47-52.

4 Sjoblom T, Shimizu A, O’Brien KP, Pietras K, Dan Cin P, Buchdunger E, Dumanski JP, Ostman A, Heldin CH: Growth inhibition of dermatofibrosarcoma protuberans tumors by the platelet-derived growth factor receptor antagonist STI571 through induction of apoptosis. Cancer Res 2001;61:5778-5783.

5 Kerob D, Porcher R, Verola O, Dalle S, Maubec E, Aubin F, D'Incan M, Bodokh I, Boulinguez S, MadelaineChambrin I, Mathieu-Boue A, Servant JM, de Kerviler E, Janin A, Calvo F, Pedeutour F, Lebbe C: Imatinib mesylate as a preoperative therapy in dermatofibrosarcoma: results of a multicenter phase II study on 25 patients. Clin Cancer Res 2010;16:3288-3295.

-6 Bianchini L, Maire G, Guillot B, Joujoux JM, Follana P, Simon MP, Coindre JM, Pedeutour F: Complex t( $5 ; 8$ ) involving the CSPG2 and PTK2B genes in a case of dermatofibrosarcoma protuberans without the COL1A1PDGFB fusion. Virchows Arch 2008;452:689-696. 
7 Kletsas D, Pratsinis H, Gioni V, Pilichos K, Yiacoumettis AM, Tsagarakis S: Prior chronic in vivo glucocorticoid excess leads to an anabolic phenotype and an extension of cellular life span of skin fibroblasts in vitro. Ann NY Acad Sci 2007;1100:449-454.

8 Oikarinen A, Haapasaari KM, Sutinen M, Tasanen K: The molecular basis of glucocorticoid-induced skin atrophy: topical glucocorticoid apparently decreases both collagen synthesis and the corresponding collagen mRNA level in human skin in vivo. Br J Dermatol 1998;139:1106-1110.

9 Autio PA, Oikarinen A, Melkko J, Risteli J: Systemic glucocorticoids decrease the synthesis of type I and type III collagen in human skin in vivo, whereas isotretinoin treatment has little effect. Br J Dermatol 1994;131:660663.

10 Slavin J, Unemori E, Hunt TK, Amento E: Transforming growth factor beta (TGF-beta) and dexamethasone have direct opposing effects on collagen metabolism in low passage human dermal fibroblasts in vitro. Growth Factors 1994;11:205-213.

11 Mahonen A, Jukkola A, Risteli L, Risteli J, Mäenpää PH: Type I procollagen synthesis is regulated by steroids and related hormones in human osteosarcoma cells. J Cell Biochem 1998;68:151-163.

12 Schoepe S, Schäcke H, Bernd A, Zöller N, Asadullah K: Identification of novel in vitro test systems for the determination of glucocorticoid receptor ligand-induced skin atrophy. Skin Pharmacol Physiol 2010;23:139151. 